\title{
AVDS should not dethrone ARDS
}

\author{
Yazine Mahjoub ${ }^{1 *}$ (D), Daniel Rodenstein ${ }^{2}$ and Vincent Jounieaux ${ }^{3}$
}

\section{To the Editor}

We read with great interest the commentary by Gattinoni and Marini [1] trying to "accommodate the discordant and inconvenient Covid-19 observations." In their analysis, the authors suggest to modify, rearrange, rethink the Adult Respiratory Distress Syndrome (ARDS) and even abandon it because in the early stage of COVID-19, lungs are unusually compliant and gas filled end thus differ from ARDS related to other diseases. We agree that COVID-19 atypical early presentation required a specific and unusual treatment. However, this does not imply that we should abandon the term ARDS and all physiopathology and logic that lies behind it. This acronym has helped to promote lung protective strategy, Peep trial, prone positioning and recruitment maneuvers that have saved many lives, or at least have avoided adding iatrogenic injury to disease-related lung insults. At the start of the first wave of the COVID-19 pandemic, we proposed to consider COVID-19 as, indeed, a new type of disease that we termed AVDS (Acute Vascular Distress Syndrome), that affects vessels, mainly pulmonary vessels, leading to an intrapulmonary shunt [2]. COVID-19 is histologically characterized with lung endothelium damage and significant neo-angiogenesis. This pattern has also been characterized on thoracic imaging (pulmonary arterial dilatations on CT-scan, areas with increased pulmonary flow on dual energy CT-scan or on late images from ventilation-perfusion pulmonary scintigraphy [3]).

This comment refers to the article available online at https://doi.org/10.1186/ s13054-021-03748-6.

*Correspondence: Mahjoub.Yazine@chu-amiens.fr

${ }^{1}$ Cardiac Vascular Thoracic and Respiratory Intensive Care Unit, Department of Anaesthesia and Intensive Care, Amiens University Medical Centre, Amiens, France

Full list of author information is available at the end of the article
This early vascular insult explains the so-called mysterious happy hypoxia [4], ICU presentation with increased compliance, low recruitability [5], increased cardiac output with low vascular pulmonary resistances and increased intrapulmonary shunt. Some other ICU data have support the AVDS concept showing relative inefficacy of arterial vasodilatator agent such as iNO and the benefit of the arterial vasoconstrictor agent almitrine. All these observations led us to propose the acronym AVDS to describe the early stage of the COVID-19 disease [2]. With the progression of the disease appeared the alveolar insult (which may be more the consequence of the endothelium injury than a direct alveolar injury) that hides the persisting vascular insult. At this time, if the alveolar injury overcomes the vascular one, the presentation may be a typical ARDS and patients may still require the classic ARDS treatments including the ARDS recommended lung protective strategy.

Therefore, we consider it more useful and truthfully to add AVDS to ARDS rather than to abandon a concept that has proved useful and still keeps all its sense.

\section{Authors' response \\ J. J. Marini ${ }^{4}$ and L. Gattinon ${ }^{5}$ \\ *Correspondence: gattinoniluciano@gmail.com \\ ${ }^{4}$ Department of Pulmonary and Critical Care Medicine, University of Minne- sota and Regions Hospital, St. Paul Minnesota, USA. \\ ${ }^{5}$ Department of Anesthesiology, University Medical Center Göttingen, Robert-Koch Straße 40, 37075 Göttingen, Germany}

\section{To the Editor,}

We appreciate the thoughtful letter of Mahjoub and colleagues, whose perspective, while somewhat differently expressed, is quite compatible with ours. Our correspondents apparently read the title of our commentary original author(s) and the source, provide a link to the Creative Commons licence, and indicate if changes were made. The images or other third party material in this article are included in the article's Creative Commons licence, unless indicated otherwise in a credit line to the material. If material is not included in the article's Creative Commons licence and your intended use is not permitted by statutory regulation or exceeds the permitted use, you will need to obtain permission directly from the copyright holder. To view a copy of this licence, visit http://creativecommons.org/licenses/by/4.0/. The Creative Commons Public Domain Dedication waiver (http://creativeco mmons.org/publicdomain/zero/1.0/) applies to the data made available in this article, unless otherwise stated in a credit line to the data. 
but seem not to have digested the spirit of our text. Certainly, we did not intend in our choice of a deliberately provocative title to encourage an abandonment 'all the physiology and logic that lies behind' the label of ARDS. Indeed, we have devoted much of our investigative careers to defining more clearly the drivers of acute lung injury and its safe management. We seem to both agree that the label of ARDS is a very broad problem category that requires more than one treatment approach, depending on its specific cause. COVID pneumonia has provided a good example of what can go wrong with a standardized 'lung protective' prescription, as both of our groups have argued in the literature. (We also agree with Majhoub and colleagues that the term AVDS may indeed a step toward directing our clinical focus on the actual respiratory disturbances of this acute, and progressive lung affliction-and to avoid the errors of using 'standardized' dictates for ARDS ventilation therapy.) We might disagree, however, that the acronym ARDS itself has 'helped promote lung protective strategy, PEEP strategy, prone positioning, recruitment maneuvers that have saved many lives.' Deeper understanding of the varied forms and properties of acute lung injury, patient ventilator interactions and the hazards of VILI did. Indeed, the lumping of patients into that unifying label in RCTs has contributed to the obfuscation of the nuances of appropriate treatment. Sounding the 'fire alarm' bell of ARDS does not tell you what is causing the conflagration nor how best to address the hazard. In our opinion, ARDS should be viewed much like the terms chronic heart failure $(\mathrm{CHF})$ and renal failure. $\mathrm{CHF}$ does not have a single approach, but one based on personalized data collection, a pathophysiologic understanding of what is causing the disturbance, and a logical approach to its therapy. We thank Mahjoub and colleagues for reinforcing the central gist of our intended message.

\section{Acknowledgements}

Not applicable.

\section{Authors' contributions}

$\mathrm{YM}, \mathrm{VJ}$ and DOR contributed to design and writing of the draft. All authors read and approved the final manuscript.
Funding

Only institutional funds from Amiens University Medical Centre were used for this study.

Availability of data and materials

Not applicable.

\section{Declarations}

Ethical approval and consent to participate

Not applicable.

\section{Consent for publication}

Not applicable.

\section{Competing interests}

The authors declare that they have no competing interest.

\section{Author details}

${ }^{1}$ Cardiac Vascular Thoracic and Respiratory Intensive Care Unit, Department of Anaesthesia and Intensive Care, Amiens University Medical Centre, Amiens, France. ${ }^{2}$ Pneumology Department, Cliniques Universitaires Saint-Luc, Université Catholique de Louvain, Brussels, Belgium. ${ }^{3}$ Pneumology Department, Amiens University Medical Centre, Amiens, France.

Received: 20 October 2021 Accepted: 22 October 2021

Published online: 18 November 2021

\section{References}

1. Gattinoni L, Marini JJ. Isn't it time to abandon ARDS? The COVID-19 lesson. Crit Care. 2021;25(1):326

2. Mahjoub Y, Rodenstein DO, Jounieaux V. Severe Covid-19 disease: rather AVDS than ARDS? Crit Care. 2020;24(1):327.

3. Jounieaux V, Mahjoub Y, EI-Esper I, Rodenstein DO. The importance of lung hyperperfusion patterns in COVID-19-related AVDS. Eur J Nucl Med Mol Imaging. 2021;48(10):3022-3.

4. Jounieaux V, Rodenstein DO, Mahjoub Y. On happy hypoxia and on sadly ignored "acute vascular distress syndrome" in patients with COVID-19. Am J Respir Crit Care Med. 2020;202(11):1598-9.

5. Abou-Arab O, Haye G, Beyls C, Huette P, Roger PA, Guilbart M, Bernasinski M, Besserve P, Trojette F, Dupont H, Jounieaux V, Mahjoub Y. Hypoxemia and prone position in mechanically ventilated COVID-19 patients: a prospective cohort study. Can J Anaesth. 2021;68(2):262-3.

\section{Publisher's Note}

Springer Nature remains neutral with regard to jurisdictional claims in published maps and institutional affiliations. 